\title{
Laryngeal Trauma
}

https://doi.org/10.47210/bjohns.2021.v29i1.453

Gurbax Singh, ${ }^{1}$ Sumit Prinja, ${ }^{1}$ Suchina Parmar, ${ }^{1}$ Garima Bansal, ${ }^{1}$ Simmi Jindal ${ }^{1}$

$\underline{\text { Introduction }}$

\section{ABSTRACT}

Laryngeal trauma can be an immediately life-threatening entity. Failure to recognize such injuries and delay in securing the airway may have fatal results. Early diagnosis and accurate evaluation with proper treatment is vital.

Materials and Methods

Fifteen patients with laryngotracheal injuries were analyzed prospectively. The outcome was assessed both in terms of voice and airway, on short term and long term basis.

\section{$\underline{\text { Result }}$}

Commonest cause of injury was suicidal followed by road traffic accidents and strangulation. The main presenting symptoms and signs were stridor, hoarseness, haemoptysis and odynophagia. Five patients suffered penetrating trauma and ten patient sustained blunt trauma. Sites of laryngeal injury included; hyoid bone fracture, mixed soft tissue and cartilaginous injuries, thyrohyoid membrane and cricothyroid membrane injuries. Eleven patients presented within 24 hours of the injury. Outcome (airway and voice) was good in ten patients whereas it was poor in three patients. Poor results were seen in patients who had delayed surgical intervention.

\section{$\underline{\text { Conclusion }}$}

Early surgical intervention is recommended for traumatic laryngeal injuries to ensure a good outcome; which further depends upon patient's condition, injury and treatment-specific factors.

$\underline{\text { Kevwords }}$

Neck Injuries; Larynx; Wounds, Penetrating; Wounds, Nonpenetrating

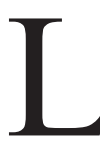
aryngeal trauma can be potentially lifethreatening. Injuries can be blunt, penetrating, inhalational, injury caused by caustic ingestion, post intubation and iatrogenic. Blunt injuries represent only $5 \%$ of all neck trauma, but can be very challenging to assess since its presentation is often delayed. Penetrating injuries, on the other hand are more common and even when they seem to be only superficial and minor, always need thorough investigation and observation. ${ }^{1}$

Acute blunt laryngeal trauma can be a life threatening event and often poses a difficult airway problem. Blunt injuries to the anterior neck are most commonly due to road traffic accidents. This occurs when the driver's extended neck hits the steering wheel or dashboard.

1 - Department of ENT, GGS Medical College, Faridkot

\section{Corresponding author:}

Dr Sumit Prinja

email: prinja2001@gmail.com
The incidence of such types of injuries are decreasing probably due to strict laws pertaining to seat belts, presence of airbags and decreased drunken driving. ${ }^{2}$

External laryngeal trauma, which is often a part of head and neck trauma, per se is a relatively uncommon injury estimated at approximately 1 in every 22,900 emergency room visits. ${ }^{3}$ The anterior neck injuries are accidental, suicidal or homicidal in nature. The individual with penetrating anterior neck injury (cut throat injury) presents with airway compromise, aspiration or acute blood loss with hypoxemia because of the airway injury and the injury to major vessels in the neck. ${ }^{4}$ The time since injury till patient lands in emergency has a big prognostic value in regards to decreasing morbidity and mortality.

The presenting symptoms often do not correlate well with the severity of the injury and injuries may range from an endolaryngeal hematoma to a complete tracheal transection. Injury to the larynx can result in serious airway problems and impaired voice production if not 
Table I: Schaefer classification system for determining the severity of laryngeal injuries

\begin{tabular}{|c|c|}
\hline GROUP & SEVERITY OF INJURY \\
\hline 1 & $\begin{array}{c}\text { Minor endolaryngeal hematomas } \\
\text { or lacerations without detectable } \\
\text { fractures }\end{array}$ \\
\hline 2 & $\begin{array}{c}\text { More severe edema, hematoma, minor } \\
\text { mucosal disruption without exposed } \\
\text { cartilage, or non-displaced fractures }\end{array}$ \\
\hline 3 & $\begin{array}{c}\text { Massive edema, large mucosal } \\
\text { lacerations, exposed cartilage, } \\
\text { displaced fractures or vocal cord } \\
\text { immobility }\end{array}$ \\
\hline 4 & $\begin{array}{c}\text { Same as group 3, but more severe with } \\
\text { disruption of anterior larynx, unstable } \\
\text { fractures, two or more fracture lines, } \\
\text { or severe mucosal injuries }\end{array}$ \\
\hline 5 & \begin{tabular}{c} 
Complete laryngotracheal separation \\
\hline
\end{tabular} \\
\hline
\end{tabular}

diagnosed promptly. Accurate diagnosis of the extent of the injury can be achieved with a combination of high resolution computed tomography, flexible fibreoptic laryngoscopy and flexible bronchoscopy.

The most important goal in management is to first secure and reconstruct the airway. Once this has been achieved, the long-term goal of treatment is to restore the voice, breathing and swallowing mechanism. Through this article we wish to audit our approach to this relatively infrequent injury and to share our experience.

\section{Materials and Methods}

The present study analyses our experience with fifteen cases of external laryngeal trauma both blunt and penetrating seen over a period of five years. Fifteen patients with external laryngeal trauma from 2014 to 2019 were managed and prospectively followed for 1 year.

All patients initially presented to the emergency department of GGS Medical College and Hospital, Faridkot and were referred to the ENT department for management. Patients were evaluated for their airway and voice quality.

\section{The following features were noted:}

Underlying cause of the injury, airway management, symptoms, severity of injury, site of injury, treatment and outcome.

Schaefer Classification System was used to grade the severity of laryngeal injury. ${ }^{5}$

We analysed retrospectively their clinical presentation, diagnosis, management, sequela and final outcome both in terms of voice and airway on short term and long term basis.

\section{Results}

A total of fifteen patients with ages between 8 to 50 years were assessed and formed the basis of the study. There were eleven male $(73 \%)$ and four female $(27 \%)$ patients. Five patients suffered penetrating injury and ten patients sustained blunt trauma.

The commonest cause of laryngeal trauma was suicidal; seen in $33 \%$ of patients followed by road side accidents and accidental strangulation.

Out of total fifteen cases, five cases were suicidal (33\%), three cases were road side accidents $(20 \%)$, three cases of accidental strangulation $(20 \%)$ and two patients sustained injury following assault (13\%). One patient $(7 \%)$ presented with dog bite on anterior aspect of the neck causing penetrating injury. One patient (7\%) presented with accidental ingestion of hot boiling water causing laryngopharyngeal burns. (Fig. 1)

Out of total three road side accidents $(20 \%)$ one case of vehicular accident suffered blunt trauma and two cases suffered penetrating trauma. Accidental strangulation in three patients $(20 \%)$ was due to a loose cloth (dupatta) worn around the neck causing strangulation.

Out of total fifteen patients, eight presented with stridor. Emergency tracheostomy was performed in these eight patients. In rest seven patients, airway was adequate and no tracheostomy was required.

Hoarseness was found in seven patients. Other symptoms suggesting laryngotracheal injury included haemoptysis (5 patients) and odynophagia (10 patients). (Fig. 2)

According to the Schaefer's classification, five 


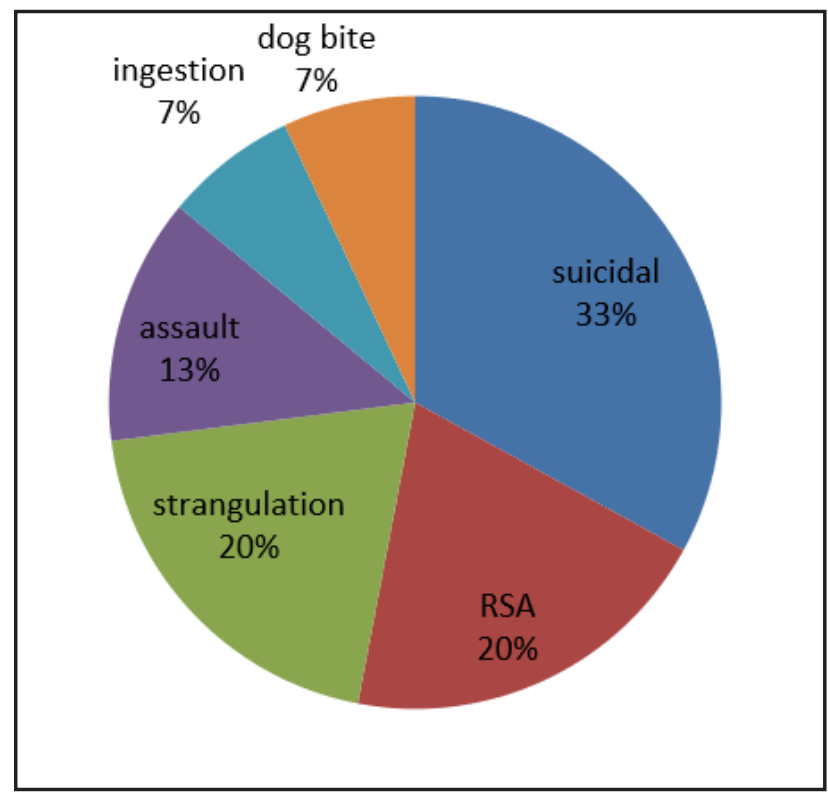

Fig. 1. Causes of laryngeal trauma

patients classified under the grade 1 injury, five patients under grade 2 injury, three patients under grade 3 and two patients under grade 5 injury.

On indirect laryngoscopy, we found two patients had left vocal cord palsy. Only one patient had fracture of hyoid bone. Nine patients had soft tissue injuries alone. Disruption of cartilaginous framework (including thyrohyoid membrane, cricothyroid membrane) was found in six patients.

However, out of all fifteen patients, three patients again landed in the emergency ward with distress and we have to do the revision tracheostomy. We further investigated these patients and found the cause of respiratory distress to be subglottic stenosis with varying grades. Fig. 3a showing endoscopic picture of subglottic stenosis of 12 year old girl child presented with respiratory distress in emergency after getting accidental strangulation by dupatta during playing. Her preoperative lateral and anteroposterior neck X-ray views were normal. (Fig. 3b)

Patients underwent either medical or surgical treatment or both, depending on the type or severity of the injury. Medical treatment consisted of observation, voice rest, oral steroids, antibiotics, antireflux, humidified oxygen and saline nebulisations. Five patients were managed conservatively.

Fig. 4a shows an 8 year old girl presented with abrasions and bruise over the anterior aspect of neck during accidental strangulation by dupatta during playing. Her lateral view neck X-ray was normal. (Fig. $4 \mathrm{~b})$ She was managed conservatively and was followed

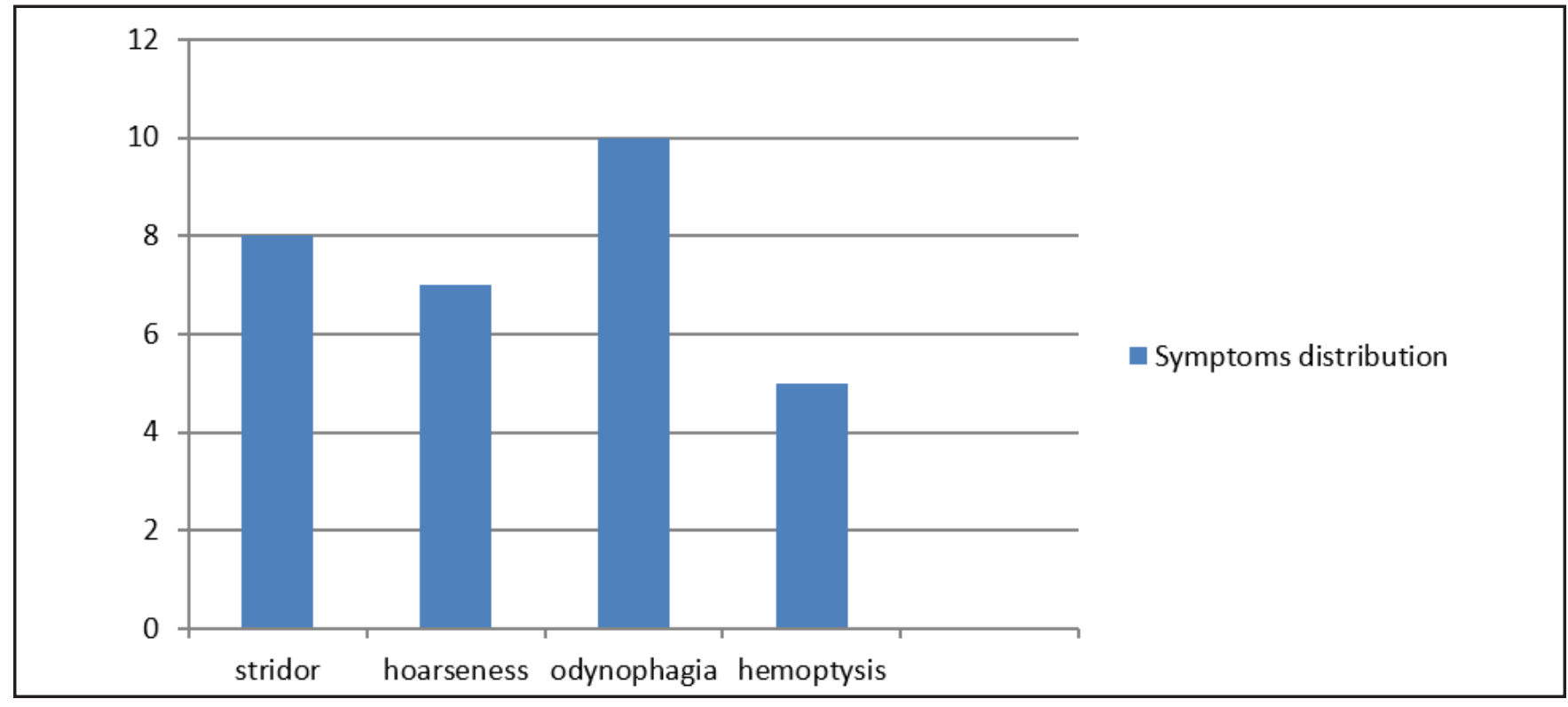

Fig. 2. Symptoms distribution among patients with laryngeal trauma . 


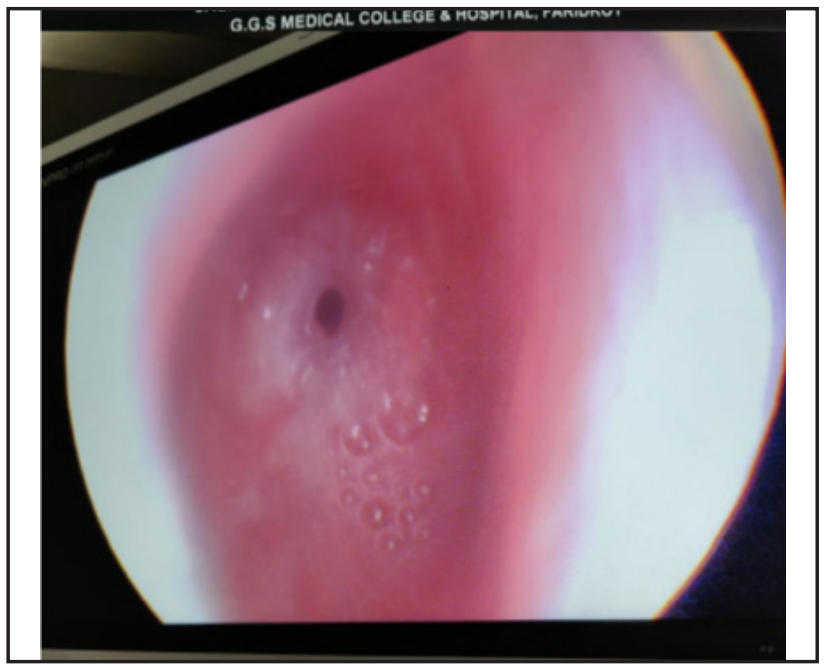

Fig. 3a. Endoscopic picture of subglottic stenosis in $\mathbf{1 2}$ yr old girl.

up monthly for 6 months. (Figs. 4c and 4d)

Surgical treatment consisted of tracheostomy and/or laryngeal exploration and repair. Out of total ten patients whom we managed surgically, only tracheostomy was required in two patients with severe laryngeal oedema or large haematoma. Two patients required only primary suturing. (Figs. 5a, 5b and 6a,6b) Two patients required both tracheostomy and primary suturing as in Figure 7a and $7 \mathrm{~b}$.

Four patients required laryngeal repair. This included

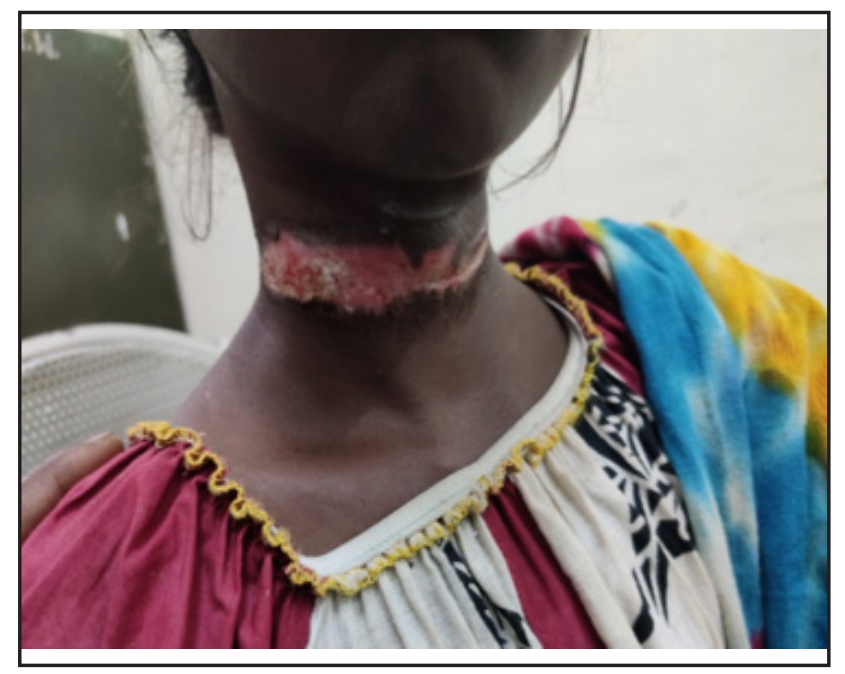

Fig. 4a. Accidental strangulation

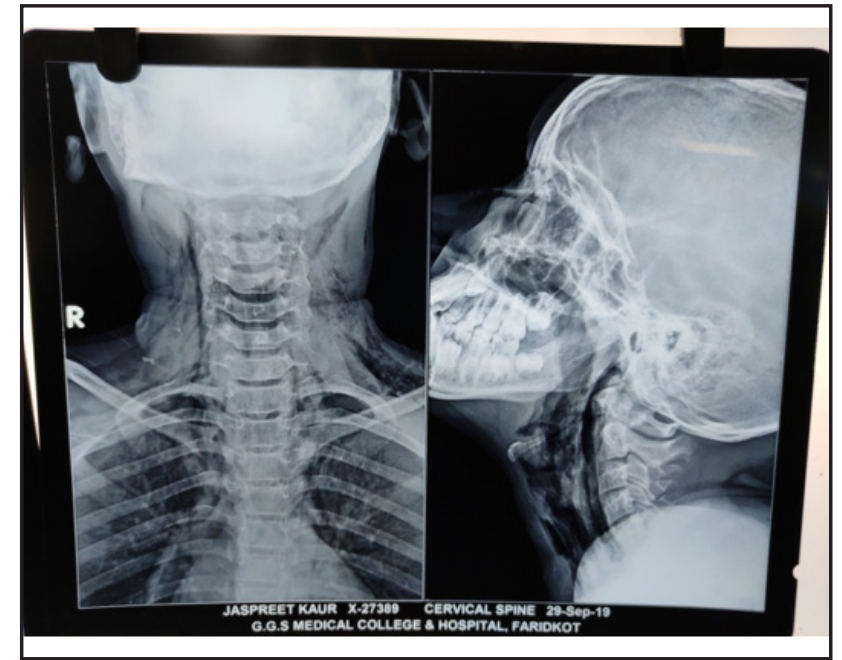

Fig. 3b. showing lateral and AP neck X-rays of the same patient presented with distress.

repairs of mucosal tears and reduction of fractures. Out of these four cases, three cases required partial cricotracheal resection and anastomosis. (Figs. 8a \& 8b)

In our study, three patients presented within one week of the trauma. Majority of patients $(73 \%)$ presented within 24 hours of the injury. Only one patient presented late $(>1$ month).

The follow-up period ranged from one month to one year. There were 2 mortalities one owing during resuscitation and other due to associated chest and head

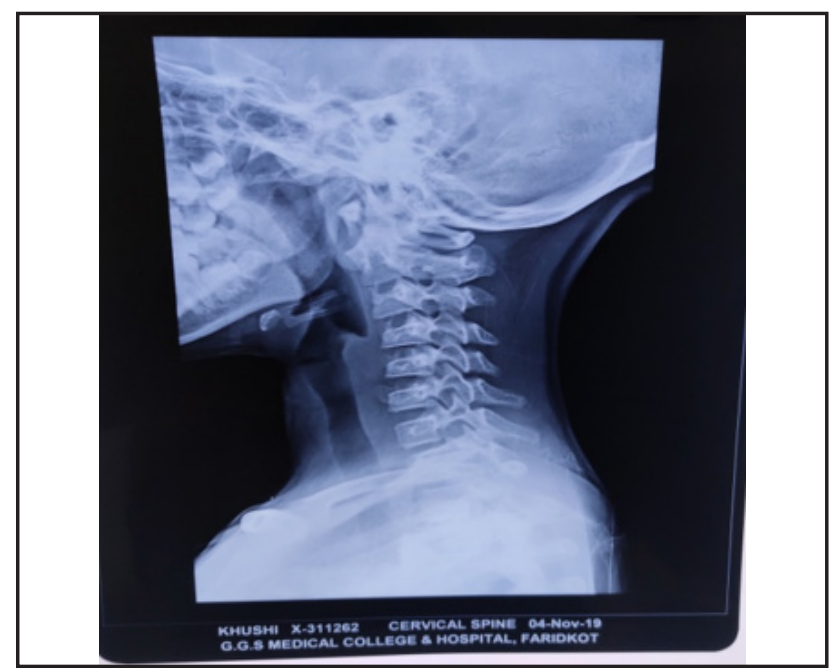

Fig. 4b. showing normal lateral view $X$-ray neck of the same patient. 


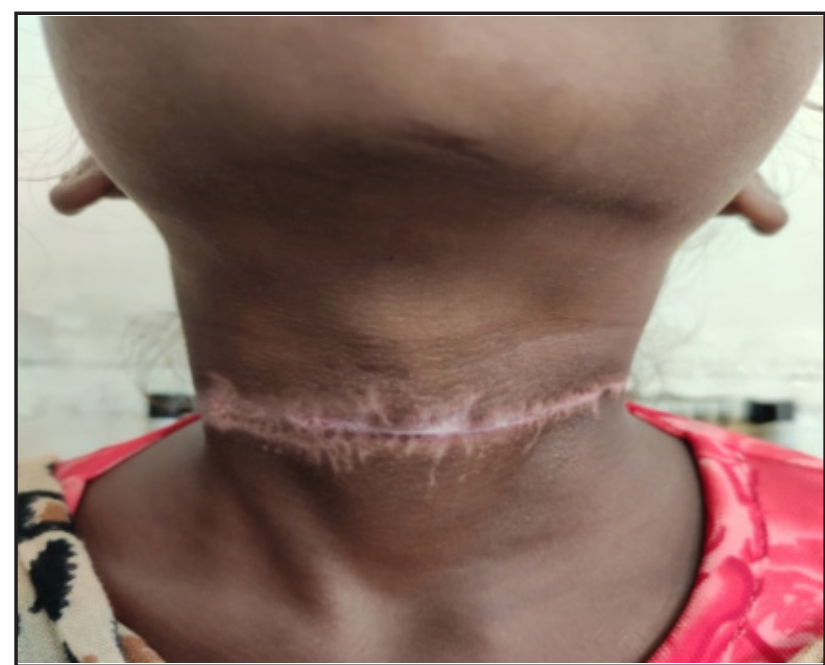

Fig. 4c. during follow up period of 2 months.

trauma.Outcome was assessed in terms of airway and voice. A good outcome was defined as that in which the patient had a normal airway or could be decannulated along with a good or fair voice. Patient's voice was evaluated regularly after 3 months.

All five patients who were managed conservatively had a good outcome.Out of total eight patients who were managed surgically, five patients who had early surgical intervention (within 7 days) did well while three patients managed by delayed surgery had poor outcome. Thus early surgical intervention was associated with a significantly better outcome.

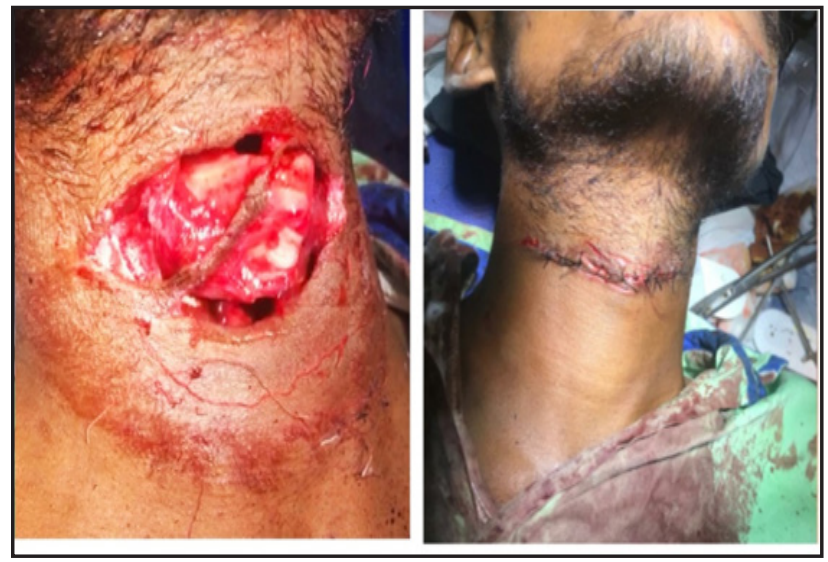

Fig. 5a \& 5b. Primary suturing

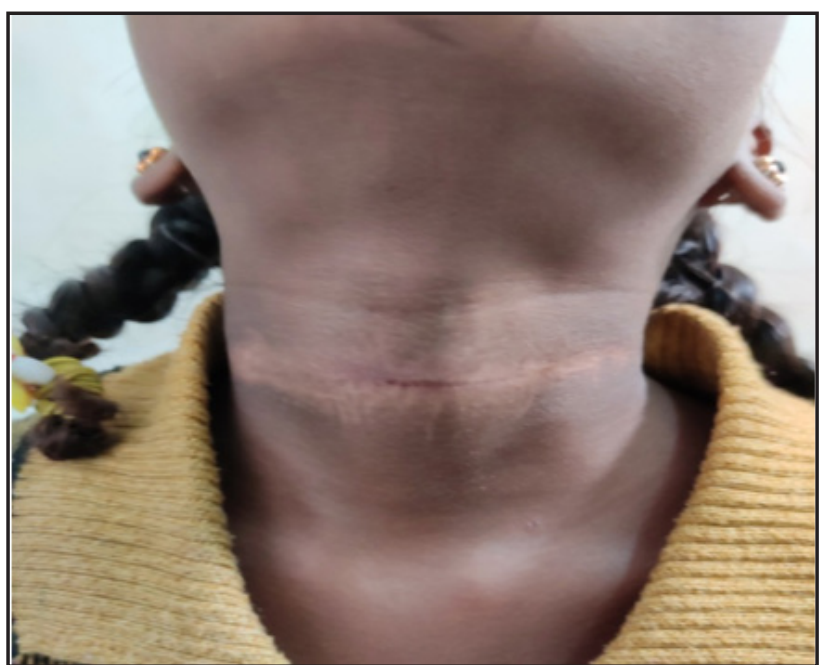

Fig. 4d. during follow up period of 3 months.

\section{Discussion}

Experience in managing laryngeal trauma is limited even in many major trauma centres due to the rarity of injury. In this study, we aim to summarize the current knowledge of blunt and penetrating injuries to the neck. Laryngeal injury is uncommon as anteriorly the inferior projection of the mandible affords significant protection and posteriorly the larynx is protected by the rigid cervical spine.

The reported overall incidence of traumatic laryngeal injuries is relatively low and ranges between 1 in 5000 to 1 in 137000 emergency room admissions. ${ }^{5,6,7}$ These

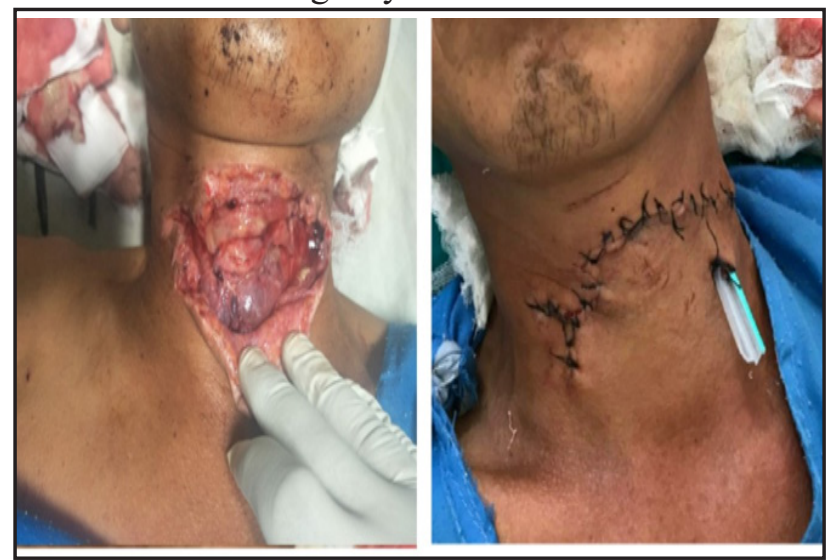

Fig. 6a \& 6b. Primary suturing 


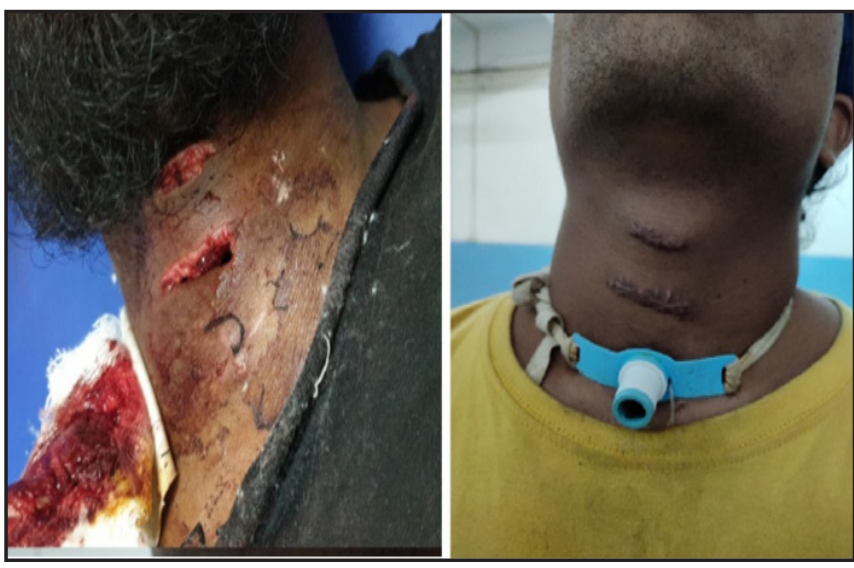

Fig. 7a \& 7b. Managed by tracheostomy and primary suturing

injuries occur most commonly in young males ( 80 per cent) ranging in age from 24 to 37 years and usually result from blunt trauma or a penetrating wound. ${ }^{5,6}$ Females tend to have slimmer, longer necks, predisposing them to a higher susceptibility to laryngeal injury, in particular supraglottic injury. However, males (77\% vs. $33 \%$ ) tend to present with the highest percentage of traumatic laryngeal injuries, secondary to greater participation in violent sports and other activities as fighting. ${ }^{6,8,9}$ In our study also males were predominantly involved.

Mortality rates from injury involving the laryngotracheal complex range from 2 to 18 percent. $^{6}$ Although blunt laryngeal trauma is associated with significant sequelae. Chagnon and Mulder reported that penetrating wound injuries were more likely to result in death. ${ }^{10}$ This mortality rate may be related to the higher likelihood of concomitant injury involving critical organs or tissues including the chest, skull base and/or critical neurovascular structures from gun or knife injuries. ${ }^{11,12,13,14}$ This is in contrast to the review by Bhojani et al. who reported a higher mortality rate in patients with blunt trauma. ${ }^{15}$

In our experience there were two mortalities in patients, one was because of associated chest and head injuries and other was due to late presentation to hospital from the site of injury and hence delayed resuscitation. The patient is examined for evidence of airway obstruction, which may present as stridor and use of accessory muscles. A cervical collar or sandbags should be used to stabilize the neck until cervical spine

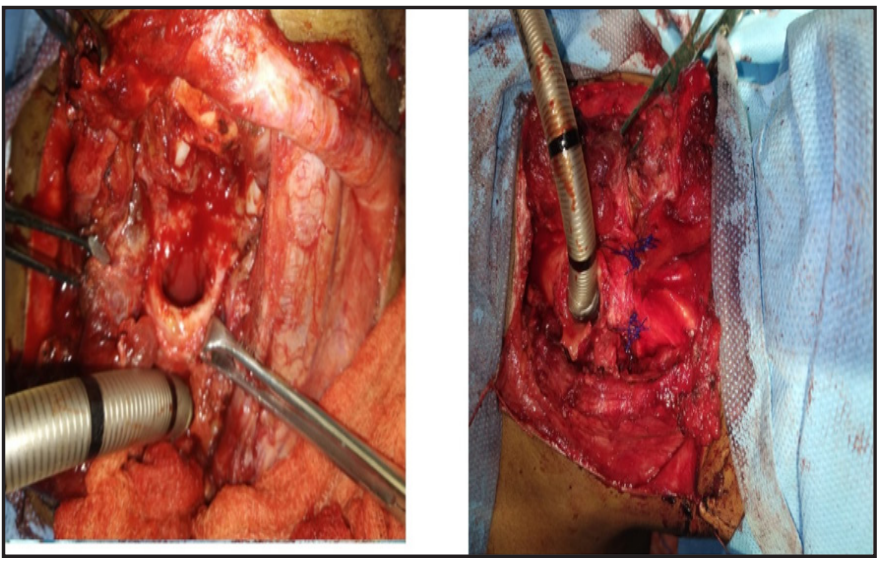

Fig. 8a \& 8b. Intraoperative picture of cricotracheal anastomosis

injury is excluded.

Treatment for primary airway control includes simple endotracheal intubation, fibreoptic awake intubation and/ or tracheostomy under local anaesthesia. Occasionally, an emergency cricothyroidotomy may be required and/or an open tracheostomy to secure the airway and to exclude any significant injury, such as cricotracheal separation. ${ }^{5}$ Gussack et al. recommend that endotracheal intubation is performed by the most experienced anaesthesiologist using a small-sized tube under direct visualization for minor laryngotracheal disruption and/or a supraglottic haematoma. ${ }^{16}$ This study reported successful intubation in eight of 11 patients with acute laryngeal trauma. Because endotracheal intubation is extremely challenging and difficult in these patients, Schaefer recommends a tracheostomy under local anaesthesia in patients with signs or symptoms of potential airway obstruction. ${ }^{17} \mathrm{~A}$ failure rate as high as 76 per cent of cases of laryngotracheal injury has been reported with intubation. ${ }^{18}$ There is also a significant risk of iatrogenic injury to the already compromised airway and/or other neurovascular structures (cervical spine), which may lead to potentially devastating sequelae. ${ }^{17}$ In cases of cricotracheal separation, blind' placement of an endotracheal tube across the area of separation can convert a stable situation to one that is life threatening. In our scenario we did tracheostomies in all cases which proved to be successful. In one of the case with blowing wound we did intubation to prevent bleeding into the airway as patient was unconscious. 
Once the airway has been established, further evaluation of the laryngotracheal injury can be performed. A variety of laryngoscopes, microlaryngeal instruments and rigid telescopes facilitate the precise examination of the endolarynx.

In patients with acute traumatic injuries, the goal of treatment is to stabilize the fracture and to promote normal soft tissue healing. Schaefer and Close reported good functional outcome following a non-operative approach in patients with minor mucosal lacerations (excluding the anterior commissure region or free edge of the vocal fold) and undisplaced, single fractures of the laryngeal cartilaginous framework. ${ }^{7}$ Bent et al. reported normal airway and phonatory function in patients with non-displaced thyroid cartilage fractures and minimal intralaryngeal injury who were treated without surgery. ${ }^{5}$ This approach included at least 24 hours of close observation in an intensive care or high dependency unit constant humidification, voice rest and elevation of the head of the bed. A subset of patients may require establishment of a safe airway (intubation or tracheostomy) and a panendoscopy to rule out concomitant injury to structures within the upper aerodigestive tract. If this examination is negative and no other indication for surgical exploration is found, these patients can be effectively managed non-operatively.

Close observation and frequent reassessment by those experienced in managing these patients are required to ensure satisfactory healing and successful extubation or decannulation. In 1956, Fogelman and Stewart reported that mortality for patients not explored immediately was 35 versus 6 percent for those who had been explored promptly. They concluded that all penetrating neck wounds that violated the platysma required surgical exploration. ${ }^{19}$ Mandatory exploration of the neck whenever the platysma muscle had been breached became common practice. Stone questioned the need for mandatory exploration for civilian injuries in $1963 .{ }^{20}$ Since that time there has been controversy about the relative merits of mandatory exploration versus selective exploration for low velocity gunshot and sharp penetrating wounds of the neck. The majority of trauma centres now advocate some form of selective conservative management. ${ }^{21}$ In our scenario we did exploration in patients who presented with distress after tracheostomy and in rest of cases it was either conservative or tracheostomy with primary suturing.

The goal of surgical intervention involving the laryngotracheal complex is to restore primary function, including ventilation, airway protection and phonation. Significant debate and controversy exists in the literature regarding the indications for surgery, its timing, method of repair and the use of intraluminal stenting. The surgical procedures used for laryngotracheal repair can range from simple suturing of cut ends i.e circumferential tracheal anastomosis to combined cricotracheal resection with anastomosis with or without use of endoluminal stents, Vocal cord repair via open approach, reduction and fixation of fractured and displaced cartilage .

The ideal timing for surgical intervention is associated with significant controversy and debate in the literature. Some recommend that a period of observation is required prior to surgery to allow any significant oedema in the upper aerodigestive tract to subside. However, others recommend exploration within 24 to 48 hours, to avoid the establishment of active infection and early scar formation. ${ }^{7,22}$ The potential long-term result of significant delay are airway and voice dysfunction. ${ }^{16,23}$ A recent multi-institutional review of 392 patients with external laryngeal trauma reported that 80 per cent of surgical interventions were performed within 48 hours of the injury, supporting early surgical exploration as the preferred standard of care. ${ }^{6}$

\section{Conclusion}

Advancements in the assessment and management of patients with trauma to the laryngotracheal region have led to enhanced patient outcome and health-related quality of life. Improvements in imaging and fibreoptic endoscopy have facilitated the evaluation of patients with acute trauma and more chronic stenotic lesions. Successful outcome following traumatic laryngotracheal injuries depends upon patient, injury and treatmentspecific factors. 


\section{References}

1. Rathlev NK, Medzon R, Bracken ME. Evaluation and management of neck trauma. Emerg Med Clin North Am. 2007; 25(3):679-94

2. Kohli A, Bhadoria P, Bhalotra A, Anand R, Goyal P. An unusual laryngeal injury. Indian J Anaesth. 2007; 51(1):57-9

3. Kandogan T, Olgun L, Gültekin G, AydarL, Mercan B, Ozuer ZM. External laryngeal trauma. Swiss Med Wkly. 2003; 133:372

4. Adebola SO, Ologe FE, Ogunkeyede SA, Adedayo GA, Ogundoyin OA. Penetrating anterior neck injury: a multidisciplinary approach. IOSR J Dent Med Sci. 2014; $13: 20-4$

5. Schaefer SD. The acute management of external neck trauma. A 27-year experience. Arch Otolaryngol Head Neck Surg. 1992; 118:598-604

6. Bent JP, Silver JR, Porubsky ES. Acute laryngeal trauma: a review of 77 patients. Otolaryngology-Head and Neck Surgery 1993;109: 441-9

7. Jewett BS, Shockley WW, Rutledge R. External laryngeal trauma analysis of 392 patients. Archives of OtolaryngologyHead and Neck Surgery 1999; 125:877-80

8. Schaefer SD, Close LC. Acute management of laryngeal trauma. Annals of Otology Rhinology and Laryngology 1989; 98:98-104

9. Fuhrman GM, Stieg FH, Buerk CA. Blunt trauma: classification and management protocol. Journal of Trauma 1990; 30:87-92

10. Maran AGD. Trauma and stenosis of the larynx. In: ScottBrowns' Otolaryngology. 6th ed. England: Butterworth Heinemann; 1997, pp 5/8/1

11. Chagnon FP, Mulder DS. Laryngotracheal trauma. Chest Surgery Clinics of North America 1996; 6:733-48

12. Henderson $\mathrm{S}$ et al. Aerodigestive tract injuries of the neck. American Journal of Surgery 2001; 67:75-9
13. Grewal H, Rao PM, Mukerji S, Ivatury RR. Management of penetrating laryngotracheal injuries. Head and Neck 1995;17 494-502

14. Croce MA et al. Laryngotracheal injuries. American Journal of Surgery $1992 ; 58: 181-7$

15. Mathisen DJ, Grillo HC. Laryngotracheal trauma. Annals of Thoracic Surgery 1987; 43: 254-62

16. Bhojani RA et al. Contemporary assessment of laryngotracheal trauma. Journal of Thoracic and Cardiovascular Surgery 2005; $130: 426-32$

17. Gussack GS, Jurkovich GJ, Luterman A. Laryngotracheal trauma: a protocol approach to a rare injury. Laryngoscope 1986; 96:660-5

18. Schaefer SD. The acute management of external laryngeal trauma: a 27 year experience. Archives of Otolaryngology Head and Neck Surgery 1992;118:598-604

19. Reece CP, Shatney CH. Blunt injuries of the cervical trachea: a review of 51 patients. Southern Medical Journal 1988; $81: 1542-7$

20. Fogelman IVIJ, Stewart RD. Penetrating wounds of the neck. American Journal of Surgery 1956; 91:391-3

21. Stone HH, Callahan GS. Soft tissue injuries of the neck. Surgery Gynecology and Obstetrics 963;117:745

22. Demetriades D, Charalambides D, Lakhoo M. Physical examination and selective conservative management in patients with penetrating injuries of the neck. British Journal of Surgery 1993; 80:1534-6

23. Leopold DA. Laryngeal trauma. A historical comparison of treatment methods. Archives of Otolaryngology Head and Neck Surgery 1983;109:106-12

24. Downey WL, Owen RC, Ward PH. Traumatic laryngeal injury - its management and sequelae. Southern Medical Journal 1977; 60:756-60. 